\title{
DESENVOLVIMENTO SUSTENTÁVEL E LIBERALISMO IGUALITÁRIO DE JOHN RAWLS
}

\author{
Amanda de Souza Gonçalves* \\ Versalhes Enos Nunes Ferreira**
}

Resumo: Texto que analisa o liberalismo igualitário de John Rawls como modelo teórico capaz de fundamentar a realização do desenvolvimento sustentável. Inicialmente, apresentamse as bases para a construção do conteúdo do desenvolvimento sustentável, que conjuga preservação ambiental, crescimento econômico e justiça social às presentes e vindouras gerações. Por fim, aborda-se a teoria da justiça como equidade rawlsiana como concepção teórica suficiente a embasar a ideia de sustentabilidade. O problema da pesquisa reside na capacidade ou não do liberalismo de Rawls em justificar o desenvolvimento sustentável. A pesquisa é do tipo teórica e baseada em fontes bibliográficas.

Palavras-chave: Desenvolvimento sustentável; Justiça como equidade; Poupança justa; John Rawls; Justiça.

\section{SUSTAINABLE DEVELOPMENT AND EQUAL LIBERALISM BY JOHN RAWLS}

Abstract: Text that analyzes the equalitarian liberalism of John Rawls as a theoretical model capable of supporting the realization of sustainable development. Initially, the basis for building the content of sustainable development is presented, which combines environmental preservation, economic growth and social justice for present and future generations. Finally, the theory of justice as Rawlsian equity is approached as a theoretical conception sufficient to support the idea of sustainability. The problem of research lies in the ability or not of Rawls's liberalism to justify sustainable development. The research is of the theoretical type and based on bibliographic sources.

Keywords: Sustainable development; Justice as equity; Just saving; John Rawls; Justice.

\section{INTRODUÇÃO}

\footnotetext{
* Mestranda em Direito, Políticas Públicas e Desenvolvimento Regional pelo Centro Universitário do Estado do Pará (CESUPA). Especialista em Direito Processual Civil pela Pontifícia Universidade Católica de São Paulo (PUC-SP). Especialista em Direito e Processo Tributário pela Universidade Estácio de Sá / Complexo de Ensino Renato Saraiva (ESTÁCIO / CERS). Bacharel em Direito pela Universidade da Amazônia (UNAMA) E-mail: amandadesg86@gmail.com. ORCID: $\quad$ https://orcid.org/0000-0001-6482-519X. http://lattes.cnpq.br/8810475833293113.

** Mestrando em Direito, Políticas Públicas e Desenvolvimento Regional pelo Centro Universitário do Estado do Pará (CESUPA) / Bolsista da Coordenação de Aperfeiçoamento de Pessoal de Nível Superior (CAPES/Brasil). Especialista em Direito Material e Processual do Trabalho pela Universidade da Amazônia (UNAMA). Bacharel em Direito pela Universidade Federal do Pará (UFPA). Integrante dos Grupos de Pesquisa "A Igualdade na Filosofia Política - Liberalismo de princípios" (UFPA/CNPq) e "Teorias da Justiça e Políticas Públicas: Fundamentação" (CESUPA/CNPq). E-mail: vfenos@gmail.com. ORCID: https://orcid.org/0000-0002-93466090. Lattes: http://lattes.cnpq.br/5838479568749865.
}

Rev. de Teorias da Justiça, da Decisão e da Argumentação Jurídica | e-ISSN: 2525-9644 | Porto Alegre | v. 4 | n. 2 | p. 16 - 37 | Jul/Dez. 2018 
A proteção do meio ambiente tornou-se um dos principais desafios do século XXI em escala global. O modo de vida das gerações pretéritas e da atual, convergiram para estabelecer um padrão de consumo dos recursos naturais que vai na contramão do ideal de preservação ambiental, beirando o verdadeiro esgotamento do patrimônio natural, com reflexos diretos à civilização do futuro.

A capacidade do ser humano em produzir externalidades negativas sem apresentar respostas eficazes de combate, apenas demonstra seu patente desinteresse pelo assunto e insciência quanto aos efeitos perversos para as vindouras gerações que, muito provavelmente, viverão sob privação de recursos ambientais hoje abundantes e que, explorados irracionalmente ao longo das gerações passadas, sentirão as consequências de sua escassez.

Neste contexto, desponta o conceito de desenvolvimento sustentável, alicerçado na ideia de harmonizar desenvolvimento econômico para o presente e conservação ambiental para o futuro, buscando a integração entre crescimento econômico, proteção ambiental e inclusão social. O propósito desta noção repousa, em última análise, na exigência de constituição de um ideal de justiça na sociedade, para esta e para as próximas gerações.

A par desta situação, o objetivo do estudo será apresentar um prisma teórico capaz de fundamentar a efetivação do conteúdo do desenvolvimento sustentável, colaborando em sua justificação e na salutar clareza sobre qual a ideia de justiça rege este conceito sistêmico. Dessarte, tomando por base o liberalismo igualitário de John Rawls, referencial teórico adotado, em especial na sua obra Uma teoria da justiça, o ensaio buscará resposta ao problema da pesquisa consistente em saber se o liberalismo de Rawls é uma teoria da justiça capaz de fundamentar a concretização plena do desenvolvimento sustentável.

$\mathrm{O}$ artigo está dividido em duas partes. Inicialmente, analisam-se as bases para a construção do desenvolvimento sustentável e a ideia de que o mesmo é fundamento para se buscar a liberdade, a equidade e a justiça no meio social. Por fim, a pesquisa trabalhará com a teoria da justiça como equidade de Rawls, apresentando as concepções do filósofo à formação de uma sociedade justa para esta e para as vindouras gerações, assim como, explorando seu ideal de justiça que embasa o conteúdo do desenvolvimento sustentável.

Em razão do problema e do objetivo proposto, o ensaio desenvolvido é uma pesquisa teórica, e que estará focada, especialmente, na obra Uma teoria da justiça em que John Rawls aborda a temática proposta, como ficará mais claro ao longo da exposição.

Rev. de Teorias da Justiça, da Decisão e da Argumentação Jurídica | e-ISSN: 2525-9644 | Porto Alegre | v. 4 | n. 2 | p. 16 - 37 | Jul/Dez. 2018 


\section{BASES CONSTRUTIVAS DO DESENVOLVIMENTO SUSTENTÁVEL}

A expressão "desenvolvimento sustentável” foi construída após uma sequência de desastres ecológicos provenientes do impetuoso crescimento econômico, unicamente preocupado com o resultado contábil positivo. É definida pelas Nações Unidas como o "desenvolvimento que procura satisfazer as necessidades da geração atual, sem comprometer a capacidade das futuras gerações de satisfazerem as suas próprias necessidades" (ONU, p. 06).

Vê-se, desde logo, que o conceito não está vinculado à proteção exclusiva da fauna e flora. Antes, quer-se confirmar que meio ambiente está, intimamente, ligado à questão da pobreza e ao bem-estar do ser humano, ou seja, liga-se à justiça social; além de existir uma singular preocupação com as gerações futuras. É como disse Montibeller Filho (1993, p. 133): "o desenvolvimento voltado para as necessidades sociais mais abrangentes, que dizem respeito à melhoria da qualidade de vida da maior parte da população, e o cuidado com a preservação ambiental como uma responsabilidade para com as gerações que sucederão".

Muito por isso o desenvolvimento sustentável deve ser visto através de uma abordagem interdisciplinar. Contudo, o termo em si apresenta incertezas quanto à delimitação do seu conceito. Isso porque, ao longo dos anos, o ideal de desenvolvimento sustentável estava tão somente voltado à ideia de que o crescimento econômico deve satisfazer o bemestar humano e, assim, alcançar um status de sustentabilidade.

Esse pensamento, na atualidade, não corresponde mais às realidades complexas e dinâmicas da humanidade. O termo sustentabilidade, desse modo, deve abranger as dimensões social, ambiental e econômica, assim como, a dimensão jurídico-política, "por se tratar de princípio constitucional gerador de novas obrigações, assim como na sua dimensão ética" (FREITAS, 2012, p. 2012). No entanto, Veiga (2010) ressalta a inconsistência com que o termo sustentabilidade vem sendo empregado por diversas comunidades internacionais. Tanto é assim que, em 1992 na Conferência das Nações Unidas para o Meio Ambiente e o Desenvolvimento, ocorrida no Rio de Janeiro, o termo foi amplamente criticado justamente por falta de precisão.

A grande discussão, consequentemente, gira em torno da expressão desenvolvimento sustentável e a sua falta de clareza conceitual, o que faz com que o uso do termo 
"sustentabilidade" seja um substituto viável e seria a capacidade de manter um determinado processo em permanência.

A sustentabilidade, no entanto, não pode ter um conceito específico porque exprime um valor. Como alerta Veiga (2010), noções de extrema importância não podem ter um conceito suficientemente claro a ponto de ter-se um amplo consenso sobre as mesmas. É como querer delimitar um conceito de felicidade. Não há um mínimo de acordo sobre o que é felicidade, apesar de ser quase unânime uma definição de infelicidade.

Aliás, o autor (VEIGA, 2010, p. 20) adverte que não há uma resposta simples para a pergunta “O que é sustentabilidade?” e seria justamente essa indefinição que acaba por restringir que sejam feitos certos exageros no emprego do termo. Então, para fins deste artigo, a discussão conceitual não é o cerne da questão, e sim, mostrar seu papel como garantidora da justiça entre as gerações presentes e futuras.

Mister se faz ressaltar a leitura que Lopes (2015) realiza de Jean-Jacques Rousseau, quando relembra que qualquer ideal de justiça social almejado pelas sociedades contemporâneas continua sendo os ideais já defendidos por aquele filósofo em sua obra " $\mathrm{O}$ Contrato Social", feitas as devidas adaptações em decorrência do tempo, e que, portanto, são anseios não defasados e, na maioria dos casos, continuam sendo apropriados à sociedade.

Segundo o autor (LOPES, 2015), o filósofo suíço enalteceu a equidade e a liberdade como bases fundamentais para uma sociedade que deseja garantir a autonomia social, e, a partir daí, afirmando os direitos inalienáveis do homem e a vontade soberana das pessoas, resultando numa governança coletiva. E, tal qual no mundo de hoje, as nações buscam convergir para que um conjunto de políticas possa efetivar o desenvolvimento sustentável.

Ocorre que, boa parte das pessoas - evidenciando o quanto o mundo continua desigual - se encontram em condições miseráveis, sem um mínimo de dignidade e sem condições de exercer a liberdade plena que lhe é inerente. E, detalhe, não somente Rousseau, mas também outros estudiosos defenderam as garantias mínimas do homem indissociáveis do valor liberdade. Nesse sentido, Sen (2002) enquadrou a liberdade como direito básico do homem, ligando-se, assim, aos princípios da sustentabilidade.

Lopes (2015) traz ainda John Rawls, outro importante filósofo que interliga conceitos como liberdade e igualdade, visando garantir a construção de uma sociedade bemordenada, justa, decente para todos seus habitantes. Para ele (LOPES, 2015), ao estudar o pensamento do filósofo liberal igualitário, aduz que ele defendera a alocação de recursos 
visando, precipuamente, beneficiar as sociedades e, por consequência, os indivíduos menos favorecidos.

A solidariedade intergeracional desponta como o grande desafio do século XXI para os Estados. Muito por isso, Lopes (2015) sugere a necessidade de reescrever um novo contrato social sem fazer com que os ideais rousseaunianos, até hoje pertinentes, se tornem meramente utópicos. E, como sair de um ideal utópico e inserir demandas práticas atingíveis, a fim de alcançar o desenvolvimento sustentável?

Apesar da indefinição conceitual de desenvolvimento sustentável, a ONU, através da Declaração do Milênio das Nações Unidas, estabeleceu objetivos e metas, levando em consideração temas como meio ambiente, direitos humanos, igualdade social e racial, tendo sido adotados por 191 países. Foram os chamados ODM - Objetivos de Desenvolvimento do Milênio, os quais foram substituídos por uma nova agenda, denominada ODS - Objetivos de Desenvolvimento Sustentável, em 2015, ampliando objetivos e metas a serem conquistados por 193 Estados (DAHL, 2015).

A primeira característica básica dos ODS é colocar o cidadão, ao lado do poder público, como parte ativa do processo para atingir a plena realização do conteúdo do desenvolvimento sustentável. Basicamente, os objetivos almejam acabar com a pobreza e a fome, reduzir as desigualdades dentro dos países, promover a industrialização inclusiva e sustentável, alcançar a igualdade de gênero, promover a sustentabilidade através dos padrões de consumo e de produção, dentre outros que, diante da realidade mundial, podem ser classificados como objetivos exigentes, pois, envolvem outras questões graves e que vêm se perpetuando ao longo de séculos.

Para Benatti (2014), a interferência desmedida do ser humano na natureza está levando ao aquecimento do planeta, às mudanças climáticas, a processos de desertificação, todavia, nada impede que alteremos essa tendência negativa e utilizemos a inteligência para adotar tecnologias limpas, a cooperação e a compreensão de que estamos vivendo em um planeta com recursos limitados. E continua afirmando que é preciso conscientização quanto à inseparabilidade entre sociedade e natureza, e, a própria sobrevivência da humanidade depende da existência da natureza, motivo pelo qual deve-se estabelecer um novo limite, uma nova forma de interação entre sociedade e natureza.

Rev. de Teorias da Justiça, da Decisão e da Argumentação Jurídica | e-ISSN: 2525-9644 | Porto Alegre | v. 4 | n. 2 | p. 16 - 37 | Jul/Dez. 2018 
Nessa toada, os ODS colocaram o homem como foco de sua agenda. Contudo, para que houvesse a efetivação das medidas estabelecidas, foi preciso reconhecer que o PIB per capita, indicador econômico usualmente utilizado para medir desenvolvimento, se tornou insuficiente por não considerar os recursos naturais e o próprio ser humano em suas avaliações.

Como disse Veiga (2010, p. 113), “a sustentabilidade só pode ser avaliada se o desempenho econômico e a qualidade de vida também puderem ser medidos com novas ferramentas, que nada têm a ver com os atuais PIB e IDH". Nesse sentido, nenhum dos indicadores representam de forma completa a qualidade do desenvolvimento, posto que o PIB liga-se, em linhas, gerais, à riqueza de um país, e, o IDH - Índice de Desenvolvimento Humano, compara países de acordo com a riqueza, educação e expectativa de vida ao nascer, para depois classificá-los em desenvolvidos e subdesenvolvidos.

As medidas de sustentabilidade precisam ir além do quantitativo econômico e visar o que, de fato, um desenvolvimento sustentável quer abarcar: a liberdade, a equidade, a justiça, o bem-estar do ser humano, nesta e nas vindouras gerações. Aliás, perseguir a justiça em sociedade deve ser a base das políticas públicas que visem ao desenvolvimento. Isso porque é a justiça incorporada nas leis, nas instituições e nos programas de ação que resultará na garantia e realização dos direitos do ser humano (MANCEBO, 2015).

E, por ter o ser humano no centro das preocupações, é que "o desenvolvimento sustentável, não qualquer desenvolvimento, é valor supremo" (FREITAS, 2016, p. 115). Com essa afirmação, portanto, Freitas (2016) ratifica o valor constitucional do desenvolvimento sustentável apresentando, inclusive, que a palavra desenvolvimento está devidamente citada no preâmbulo da Constituição Federal de 1988 (CF/88) e vai se consumando como objetivo da República, incorporando diversos comandos ao longo do texto, o que remete à transdisciplinariedade da expressão. E, como objetivo fundamental da República, se torna "norte integrativo de toda interpretação e aplicação do Direito" (FREITAS, 2016, p. 119), culminando na promoção da justiça, em especial, da justiça social.

A justiça social está, intimamente, ligada ao bem-estar das pessoas, à sua realização dentro de um corpo social organizado. Desta feita, as políticas nacionais que visam alcançar a sustentabilidade não podem se utilizar apenas do aspecto ambiental estritamente, devendo ser incluso, necessariamente, os aspectos sociais, culturais, econômicos das pessoas. O desenvolvimento sustentável, contemporaneamente, desafia não apenas as dimensões 
econômicas, social e ambiental, espraiando-se para as dimensões jurídica e política, que estão a exigir mais esforços.

Vários dispositivos da $\mathrm{CF} / 88$ fazem remissão ao desenvolvimento e à sustentabilidade, podendo-se citar o artigo $174, \S 1^{\circ}$, que fala do planejamento do desenvolvimento nacional equilibrado, o artigo 192 que ressalta que o sistema financeiro está estruturado de forma a promover o desenvolvimento equilibrado do país, e, o artigo 205 que inaugura o capítulo sobre a educação, a cultura e o desporto informando que os mesmos serão promovidos visando ao pleno desenvolvimento da pessoa, dentre outros (FREITAS, 2016).

Tal sintonia dos mandamentos constitucionais vai culminar no direito ao meio ambiente ecologicamente equilibrado, proposto pela inteligência do artigo 225 da $\mathrm{CF} / 88$, e que também é dever de todos defendê-lo e preservá-lo para as atuais e vindouras gerações.

De qualquer maneira, o que se quer, o que se pretende é reduzir a insustentabilidade, para que a espécie humana possa prolongar sua existência na Terra, utilizando racionalmente os recursos naturais e propiciando a possibilidade de que as futuras gerações usufruam de um ambiente equilibrado. Para tanto, é preciso expandir os conceitos unicamente antropocêntricos ou unicamente biocêntrico para um conceito difuso, abrangente, que inclua as liberdades e a igualdade humanas.

Por conta desta necessidade de definir uma concepção teórica que consiga fundamentar a aplicabilidade do conteúdo dos objetivos do desenvolvimento sustentável, adota-se a teoria da justiça como equidade da John Rawls, que passará a ser exposta a partir da próxima seção e que, acredita-se, possa contribuir na discussão sobre a ideia de justiça que deve permear a aplicação do conteúdo deste conceito sistêmico.

\section{O LIBERALISMO IGUALITÁRIO DE RAWLS COMO CONCEPÇÃO TEÓRICA SUFICIENTE PARA FUNDAMENTAR O DESENVOLVIMENTO SUSTENTÁVEL}

Cabe agora indicar a concepção teórica que justifica a sustentabilidade como diretiva a ser buscada pelo Estado e pela sociedade em seus atos, e que, em última análise, tem como propósito a construção de um futuro alicerçado em práticas racionais, sustentáveis, de respeito ao meio ambiente e à própria espécie humana. E, tomando por base a ideia de justiça de John Rawls (2002), inserta em sua teoria da justiça como equidade, pensa-se na concepção liberal igualitária como prisma teórico capaz de dar conta desta fundamentação quanto ao

Rev. de Teorias da Justiça, da Decisão e da Argumentação Jurídica | e-ISSN: 2525-9644 | Porto Alegre | 
desenvolvimento sustentável, notadamente pelo fato de que este direito fundamental pode ser vislumbrado como estratégia de realização da justiça, para esta e para as vindouras gerações.

Antes, convém explicitar a relevância de se discutir uma concepção teórica específica para justificar a defesa do desenvolvimento sustentável como pressuposto condicionante a que todas as pessoas possam, no presente e no futuro, usufruir de um ambiente preservado e onde haja possibilidade de perseguir seus projetos de vida, dentro de uma sociedade bem ordenada, com instituições justas e num regime democrático.

A teoria da justiça de Rawls buscou identificar princípios que seriam a base de um acordo para a construção de uma sociedade justa e para a formação de um contrato que deveria estar em ressonância com as convicções mais sólidas ou mais consolidadas na vida política de um regime constitucional. A construção de um sistema social permeado por instituições políticas e jurídicas adequadas é o sustentáculo para que cada indivíduo possa perseguir seus interesses particulares, o que será viabilizado em um contexto de meio ambiente preservado, sem descurar do crescimento econômico e dos objetivos singulares do desenvolvimento sustentável, meta a ser perseguida por Estado e sociedade.

Salvaguardar um meio ambiente equilibrado para os anos vindouros, acredita-se, fará com que a geração futura possa continuar a realizar opções de valores e ter condições de criar oportunidades visando dar curso às ações necessárias à realização de seus projetos de vida. A teoria da justiça de Rawls exsurge como possibilidade de fundamentar a diretiva da sustentabilidade no ponto em que este filósofo traz à discussão a ideia de justiça entre gerações, que significa o comprometimento ético da presente geração no que pertine à preservação de valores e bens caros às gerações futuras, bem como, no ideal de justiça em sociedade para a presente geração, possibilitando, assim, a que todos possam usufruir de um ambiente harmônico e propício à realização de seus propósitos.

O desenvolvimento sustentável alicerça-se na visão de que não haverá um verdadeiro progresso nos países se os impactos ambientais dos multifacetados projetos de desenvolvimento não são completamente levados em consideração, visto que, o ganho momentâneo com o uso de alguns recursos pode ser perdido a longo prazo, quando, então, os efeitos destrutivos deste uso se fizerem sentir e a natureza cobrará a conta no futuro pelo desenvolvimento alcançado à custa da destruição do meio ambiente existente no presente.

Ora, a concepção ecológica da sustentabilidade encontra amparo na teoria de justiça rawlsiana na medida em que esta abre espaço para discutir meios que assegurem uma 
sociedade justa no futuro, e que, por consequência, consiga deixar os cidadãos numa posição de poderem realizar escolhas valorativas e perseguirem seus planos de vida. A concepção teórica de Rawls consegue responder às demandas impostas ao desenvolvimento sustentável, no tocante à realização de justiça, em seus diversos desdobramentos.

A busca pela realização plena da democracia, dos direitos fundamentais, das liberdades básicas, combate à pobreza, proteção do planeta e garantia para que todas as pessoas possam viver em paz e com prosperidade são todos instrumentos de relevância para a exata compreensão de uma definição e implementação satisfatória do direito ao desenvolvimento sustentável. E mais, a teoria de Rawls fornece uma base teórica sólida para a aplicação de políticas públicas que visam à escorreita realização da sustentabilidade.

Frise-se que o fio condutor dos objetivos do desenvolvimento sustentável é a ideia de justiça e, acredita-se, a concepção de Rawls exposta em sua teoria da justiça acolhe essa ideia de forma natural, resultando numa convergência de ideais. Logo, a partir do momento em que se vislumbra que as ideias de desenvolvimento sustentável encontram embasamento numa teoria da justiça, in casu, na justiça como equidade, torna-se relevante, importante, discutir a questão sob o ponto de vista da concepção identificada. Argumentar a sustentabilidade e seus objetivos a partir de uma concepção teórica específica auxilia na sua compreensão, na sua importância e na necessidade de contínua implementação.

Porém, antes de ingressar na análise pertinente ao problema da pesquisa propriamente dito, faz-se necessária uma exposição sobre a teoria da justiça adotada como marco teórico. Trata-se da teoria da justiça como equidade de John Rawls, escolhida por voltar-se à questão da justiça política, da justiça oriunda da razão humana voltada à política, além dos caracteres da coerência e consistência, seja com seus referenciais, seja com o intento da pesquisa. Além disso, pertence a Rawls, segundo Fleischacker (2006), os pressupostos necessários para o moderno conceito de justiça distributiva, onde o desenvolvimento das sociedades precisa estar acompanhada com a proteção da dignidade e florescimento dos cidadãos.

\subsection{A TEORIA DA JUSTIÇA COMO EQUIDADE DE RAWLS}

Em 1971, um filósofo de Harvard, chamado John Bordley Rawls, publicou um verdadeiro tratado de filosofia política denominado Uma teoria da justiça, que ficou 
conhecido como o maior clássico da teoria da justiça, da ética jurídica, considerada um divisor de águas na história do pensamento contemporâneo. Rawls tentava responder, com base em Immanuel Kant, aos desafios do utilitarismo e ao modo de tornar racional a justificativa do liberalismo. Defendeu a liberdade, qualificada pela igualdade. Para ele, o liberalismo deve ser igualitário, ou seja, é preciso defender a liberdade de todos e para todos, não escondendo as desigualdades, que precisam ser reveladas e combatidas.

Sua obra congregou o núcleo de seu pensamento sobre a justiça, correlacionando-a para a prática política em sociedade, e revelando uma peculiaridade em sua teoria da justiça, qual seja, a opção pelo indivíduo, ou melhor, a opção por todas as pessoas, pois, em sua teoria, é inaceitável que um ser humano sobrepuje outro (BRITO FILHO, 2015). Rawls (2002, p. 04) assevera: "Cada pessoa possui uma inviolabilidade fundada na justiça que nem mesmo o bem-estar da sociedade como um todo pode ignorar". Inclusive, a própria sociedade deve proteger os indivíduos, até mesmo contra os interesses maiores dessa própria sociedade (FLEISCHACKER, 2006).

A teoria da justiça de Rawls nasce com o propósito maior de elaborar um modelo, verdadeiramente eficaz, de distribuição de bens primários na sociedade, revelando preocupação com a atenção aos menos favorecidos e priorizando o indivíduo singularmente considerado, destacando, ainda, que ao Estado cabe a função de respeitar as liberdades das pessoas, assim como, satisfazer suas necessidades básicas, não devendo descurar de ninguém. Oliveira (2003) leciona que Rawls queria demonstrar como a sociedade deveria ser para caracterizar-se como justa, e onde pessoas morais, livres e iguais possuíssem, inerentemente, senso de justiça e a faculdade de concepção do bem.

Ao construir sua teoria, denominada de "justiça como equidade", Rawls parte da chamada posição original, atrás do véu da ignorância, buscando princípios que regerão a estrutura básica da sociedade. A posição original é um recurso que celebra um acordo hipotético e a-histórico, onde representantes de cidadãos livres e iguais definem os termos da cooperação social e estabelecem princípios de justiça aptos à garantia da liberdade e da igualdade em uma sociedade democrática.

Por sua vez, o véu da ignorância representa a necessidade das partes estarem privadas da razão prática, ficando separadas de suas próprias personalidades, contingências históricas e concepções acerca da vida digna, enfim, deverão os contratantes não estarem influenciados por sua situação particular, econômica, religiosa, sexual, moral, cultural, 
intelectual, constituindo-se, assim, numa fundamental garantia da imparcialidade da concepção política de justiça de Rawls, condição para que o resultado do contrato seja justo e universal (CITTADINO, 2013).

Assim, para que o contrato social seja eivado de justiça e universalidade é fundamental que os contratantes não saibam de suas posições originais que ocupam em sociedade. Desta forma, não se saberá quem é, não se saberá o papel que ocupa na sociedade. Logo, como o contratante poderá ser o mais pobre, ou o mais rico, ou católico, ou evangélico, ou budista, enfim, jamais escolheria uma sociedade utilitária, um estado confessional, ou um estado em que a diferença econômica entre o mais rico e o mais pobre fosse abissal.

Deste modo, em uma posição original, sob o véu da ignorância, as pessoas escolheriam dois princípios que regerão a vida em sociedade, e a transformarão em uma sociedade justa. O filósofo revela, então, dois princípios: o primeiro, ligado às liberdades básicas, e o segundo, às desigualdades econômicas e sociais (TEIXEIRA, 2007). Ou seja, as pessoas escolheriam, numa posição inicial de igualdade, os princípios ou ideais da liberdade e a igualdade como valores políticos para a construção de uma sociedade justa, decente.

A justiça como equidade vem, assim, a significar que os princípios de justiça rawlsianos seriam acordados em uma situação inicial de igualdade, isto é, que tais princípios seriam considerados, eles próprios, o objeto de um acordo original em uma situação inicial adequadamente definida (BRITO FILHO, 2015).

Para Rawls (2002), os princípios de justiça vêm para beneficiar os menos favorecidos, aqui entendidos como os dotados de menos capital econômico, intelectual, cultural, educacional; almeja, em sua teoria, que estes possam usufruir de uma vida com dignidade. A sociedade justa, para Rawls, é a sociedade em que todos os indivíduos, especialmente os menos favorecidos, tenham uma vida livre, que não haja escravidão, servidão, dominação de nenhum tipo, enfim, uma sociedade isonômica, onde haja a distribuição equitativa de bens primários para todas as pessoas independentemente de seus projetos pessoais de vida. Assim, na posição original, os princípios de justiça escolhidos seriam (RAWLS, 2002, p. 333):

Primeiro princípio: Cada pessoa deve ter um direito igual ao mais abrangente sistema total de liberdades básicas iguais que seja compatível com um sistema semelhante de liberdades para todos. 
Segundo princípio: As desigualdades econômicas e sociais devem ser ordenadas de tal modo que, ao mesmo tempo: A) tragam o maior benefício possível para os menos favorecidos, obedecendo às restrições do princípio da poupança justa, e B) sejam vinculadas a cargos e posições abertos a todos em condições de igualdade equitativa de oportunidades.

O primeiro princípio externaliza a ideia das liberdades básicas, que devem ser distribuídas em nível máximo, para todos os integrantes da sociedade. Para Rawls (2002), as mais importantes liberdades básicas são: liberdade política - que inclui o direito ao voto e a ocupar cargo público, liberdade de expressão, liberdade de reunião, liberdade de consciência, liberdade de pensamento, liberdades da pessoa - proteção contra a opressão psicológica e a agressão física, direito à propriedade privada e proteção contra a prisão e detenção arbitrárias, conforme os ditames do estado de direito.

Oliveira (2003, p. 18/19) explica que, em Rawls, "a inviolabilidade das liberdades individuais está assegurada acima de todos os ajustes sociais envolvendo questões de oportunidades e desigualdades, de forma a evitar o sacrifício de indivíduos". As liberdades básicas deverão ser distribuídas a todos os indivíduos do corpo social, imparcialmente, na maior medida possível. Aqui, segundo Brito Filho (2015), é possível correlacionar a defesa destas liberdades com o tema dos direitos humanos de $1^{\text {a }}$ dimensão, isto é, direitos civis e políticos, que estão fundamentados na Liberdade.

E, o segundo princípio, formado pela igualdade equitativa de oportunidades e pela diferença (BRITO FILHO, 2015), vem com o desiderato de cuidar dos menos beneficiados pela loteria social, pregando uma distribuição equânime de renda e riqueza, direitos e deveres. Para Oliveira (2003), é neste princípio que reside o desafio da justiça distributiva. Aqui, a diferença vai amenizar a desigualdade e será fundamental para a justificação e a implementação de uma justiça distributiva que referende maiores investimentos em pessoas que vivem nas camadas mais pobres e, porque não dizer, nas camadas ambientalmente mais expostas da população.

O princípio da diferença justifica a proteção dos direitos humanos, o acesso dos pobres à Justiça, a implementação eficaz, para todos, dos serviços de saúde, educação, moradia, como também, fundamenta que todos esses direitos sejam distribuídos às expensas do Estado, notadamente com recursos arrecadados com os tributos e que devem ser direcionados, em maior volume, para a construção de escolas, para o combate à fome, para a construção de hospitais, para o fomento da assistência social, enfim, para os setores 
hipossuficientes e ambientalmente excluídos socialmente. O princípio da diferença, na prática, é o princípio de cuidar dos menos beneficiados pela loteria social, dos menos favorecidos. Vita (1993, p. 53) estabelece que:

Podemos aceitar o princípio de diferença como concepção de igualdade de uma sociedade justa - bens primários devem ser igualmente distribuídos; desigualdades nessa distribuição só são aceitáveis se também beneficiarem os mais desafortunados - não porque consideramos que talentos naturais não façam parte da identidade pessoal. (...). A justificação do princípio de diferença se apoia na ideia de que em uma sociedade democrática desigualdades imerecidas devem ser compensadas; e o estabelecimento de instituições políticas e econômicas que de formas diversas realizem essa compensação é uma pré-condição para que cada um (e não só os naturalmente privilegiados) possa exercer sua liberdade no sentido liberal do termo: a liberdade de escolher e de realizar os objetivos e fins que se julga valioso perseguir na própria vida.

Na interpretação de Brito Filho (2015), este segundo princípio ou ideal político pode ser correlacionado com a $2^{\mathrm{a}}$ dimensão dos direitos humanos, isto é, com os direitos econômicos, sociais e culturais, que estão baseados na Igualdade. E, é justamente por fundamentar seu segundo princípio de justiça na igualdade que sua teoria é considerada um marco na discussão concernente à justiça distributiva, vez que introduziu a igualdade como ideal político, rompendo com a visão de outrora do liberalismo concentrada na liberdadepropriedade privada.

Em complemento, tem-se a questão da poupança justa, inclusa no segundo princípio e que define, em linhas gerais, que é indevido à sociedade consumir o que puder ser reservado para garantir as oportunidades necessárias às gerações vindouras, desde que os menos favorecidos da presente geração não sejam prejudicados.

Os princípios que seriam escolhidos na posição original, sob o véu da ignorância, voltam-se à estrutura básica da sociedade, regem a atribuição de direitos, deveres, vantagens econômicas e sociais e acabam por representar um caso peculiar de uma concepção maior de justiça, qual seja, os valores sociais devem ser igualitariamente distribuídos, a menos que a distribuição desigual seja vantajosa para todos, sendo consideradas injustas as diferenças não benéficas à coletividade (RAWLS, 2002).

Frise-se que, para Rawls, o princípio da igual liberdade terá prioridade em relação ao segundo princípio (princípio da diferença e princípio da igualdade equitativa de oportunidades). Essa prioridade de realização traduz a chamada primazia do justo sobre o

Rev. de Teorias da Justiça, da Decisão e da Argumentação Jurídica | e-ISSN: 2525-9644 | Porto Alegre | v. 4 | n. 2 | p. 16 - 37 | Jul/Dez. 2018 
bem, “característica de modelos deontológicos (moral do dever), em contraposição a modelos teleológicos e utilitaristas (éticas das virtudes e morais hedonistas)" (OLIVEIRA, 2003, p. 18). Para o filósofo, seus princípios devem ser ordenados em uma série lexicográfica, serial, sendo o modelo mais adequado para se alcançar a total realização de seus dois princípios de justiça (BRITO FILHO, 2015). Por esse motivo, "as reivindicações da liberdade devem ser satisfeitas primeiro. Até conseguirmos isso, nenhum outro princípio entra em jogo" (RAWLS, 2002, p. 267).

John Rawls estabeleceu uma justiça distributiva igualitária, que, em nosso sentir, é a pedra de toque de sua filosofia. Ora, alguma distribuição de bens essenciais é devida a todos, na medida de suas necessidades, pelo simples fato de sermos seres humanos (FLEISCHACKER, 2006). Em verdade, é imperioso distribuir, de modo justo, os bens primários/direitos fundamentais para todos os integrantes do corpo social, e a concepção teórica liberal igualitária avançou, de maneira satisfatória, nesse sentido.

O ponto de partida para Rawls é a ideia de que uma sociedade justa deve reconhecer, em suas instituições básicas, a igualdade humana fundamental ou o valor intrínseco igual dos seres humanos (VITA, 2007). Na busca pela justiça social, o filósofo aduz que uma sociedade bem-ordenada é aquela que é regulada por uma concepção pública de justiça, ou seja, todos os integrantes aceitam e sabem que os outros aceitam os mesmos princípios de justiça e onde é sabido que as instituições sociais básicas geralmente os realizam; desta maneira, em existindo consenso nas concepções de justiça, facilitado está ao indivíduo coordenar seus planos e projetos com maior eficiência e respeitar acordos mutuamente benéficos.

Para Rawls (2002), o objeto primário da justiça é a estrutura básica da sociedade, forma pela qual as instituições sociais mais importantes a exemplo da constituição política e dos principais acordos econômicos e sociais distribuem os bens primários em sociedade. Convém repisar que o filósofo inseriu o indivíduo em posição de supremacia em sua teoria, buscando resguardar, para cada pessoa, um mínimo de bens essenciais capazes de proteger sua dignidade, evitando sua violação e promovendo sua realização, priorizou direitos e liberdades fundamentais individuais. Infere-se, muito claramente, a ideia de distribuição de bens primários com o intuito de proteção do mínimo existencial individual.

Tomando por base a interpretação realizada por Brito Filho (2015), pode-se dizer que os bens primários seriam, na atualidade, nossos direitos fundamentais, e, a responsabilidade pela sua distribuição a todos os cidadãos caberia ao Estado, em seus diversos níveis. A 
distribuição de bens primários, em Rawls, viabiliza a que as pessoas consigam realizar, efetivamente, suas metas pessoais de vida, independentemente da natureza particular do plano e de seus objetivos finais (RAWLS, 2002). Para ele, a justiça se realiza com a distribuição justa de oportunidades ou de recursos, e deve estar assegurada por princípios constitucionais, construídos sobre fundamentos morais (SCALOPPE, 2014). Aduz Dworkin (2014, p. 04/05):

Nenhum governo é legítimo a menos que endosse dois princípios soberanos. Em primeiro lugar, ele deve demonstrar igual consideração pelo destino de toda pessoa sobre a qual pretende ter domínio. Em segundo lugar, deve respeitar plenamente a responsabilidade e o direito de toda pessoa de decidir por si mesma como fazer de sua vida algo valioso. Esses princípios orientadores definem quais são as teorias aceitáveis de justiça distributiva - teorias que estipulam os recursos e as oportunidades que o Estado deve disponibilizar ao povo que ele governa.

No liberalismo igualitário o indivíduo alcança importância ímpar, é titular de direitos básicos, que não podem ser negligenciados pelo Estado, que não podem ser minorados em prol da coletividade, e que devem ser efetivados, para que possa, livremente e igualitariamente, buscar a realização de seus planos de vida. A melhor concepção tratativa da distribuição de direitos foi a definida pelos liberais igualitários, pois, para eles, tais bens devem ser distribuídos para todos. É a corrente filosófica que melhor atende à proteção da dignidade humana, pois, vislumbra-a a partir do indivíduo, e não da coletividade. Tanto o é que, a melhor concepção de justiça distributiva, das atualmente existentes, pertence a Rawls (BRITO FILHO, 2015).

Fleischacker (2006) defende que a distribuição de bens valiosos em sociedade deve alcançar todos os indivíduos, e justifica dizendo que cada pessoa, pelo simples fato de ser humana, é merecedora de direitos básicos, e, o dever de distribuir tais bens é tarefa do Estado. Alguma distribuição de bens valiosos para todos os integrantes da sociedade é medida que se impõe, por isso a ideia de justiça distributiva, em Rawls, é a melhor das atualmente existentes (BRITO FILHO, 2015).

Assim, a ideia de Justiça em Rawls perpassa pela construção de uma sociedade bemordenada, democrática, pautada no valor da liberdade qualificada pela igualdade, com instituições justas, com garantia de direitos básicos iguais, com uma distribuição equitativa de recursos sociais escassos - a exemplo de renda, riqueza, oportunidades aos seus cidadãos - e com pessoas que, usufruindo dos direitos fundamentais em sua plenitude, possuam condições de dar curso às ações necessárias para o cumprimento de seus projetos de vida.

Rev. de Teorias da Justiça, da Decisão e da Argumentação Jurídica | e-ISSN: 2525-9644 | Porto Alegre | v. 4 | n. 2 | p. 16 - 37 | Jul/Dez. 2018 
E mais, Rawls não apenas trabalhou nos pilares para a formação de uma sociedade justa, assegurando direitos não sujeitos à barganha ou ao cálculo de interesses sociais para a presente geração, também desenvolveu ideias concernentes ao exercício de direitos e deveres para as gerações futuras. A justiça, ao que se depreende das linhas filosóficas rawlsianas, exige continuidade, isto é, não se espera que uma situação seja justa momentaneamente, espera-se que seja, sim, duradoura. A concepção de justiça desenvolvida por Rawls, que abrange as gerações presentes e futuras, deve se autossustentar no tempo, deve se incorporar na estrutura básica da sociedade e levar as pessoas a adquirirem o respectivo senso de justiça e fazê-las agirem em conformidade a essa concepção.

Para Rawls (2002), cada geração deve desenvolver o senso de preservar os ganhos de sua cultura e civilização, preservar suas instituições justas, e deixar um pouco às sociedades futuras. A atual geração, que deve seguir balizada pelo princípio da poupança justa intergeracional, contribui para a manutenção das gerações futuras, e isso se perpetua e faz com que a justiça seja uma constante em sociedade, um ciclo virtuoso que liga o presente (desenvolvimento) ao futuro (sustentabilidade) da humanidade.

Se, cada geração, desenvolver a consciência de que se deve, hoje, receber de seus predecessores e repassar às gerações vindouras o que for devido, muito provavelmente viverse-á numa sociedade marcadamente justa, eis que haverá uma preocupação com os descendentes, pelo menos aos mais próximos. Um detalhe merece atenção, Rawls não diz que a geração do agora deva poupar recursos para que a geração futura seja mais rica, em verdade, a ideia é que a justiça entre gerações resulte em uma poupança capaz de promover a plena realização de instituições justas e liberdades iguais para os seres humanos do futuro, para que possam viver dignamente e consigam dar curso aos seus projetos de vida.

Rawls (2002) aduz que o sistema social precisa preocupar-se com as futuras necessidades e aspirações de seus cidadãos. Preleciona, em suas linhas, que o sistema econômico de um Estado moderno não pode ater-se na satisfação de desejos e necessidades existentes no hoje, mas também deve desenvolver um modo para se criar e modelar as necessidades das gerações do amanhã. E diz: "O modo como os homens trabalham em conjunto agora para satisfazer os seus desejos atuais afeta os desejos que eles terão mais tarde, o tipo de pessoas que virão a ser” (RAWLS, 2002, p. 286).

A construção de uma sociedade justa, no hoje, implica na preocupação de se construir uma sociedade justa para o amanhã, implica que a atual geração deve respeitar 
diretrizes para que exista justiça nas gerações vindouras, contexto em que se visualiza, de maneira clara, o cerne do desenvolvimento sustentável. Portanto, o ideal de Justiça em Rawls é, assim, defendido quanto ao presente, quanto ao contemporâneo, sem olvidar o futuro que está a exigir a tomada de decisões racionais no agora.

Como diz Brito Filho (2015), a teoria rawlsiana introduziu a igualdade como ideal político de uma sociedade que se pretenda ser justa, e acabou por romper com a visão liberal clássica - pautada no binômio liberdade-propriedade, e fixou a liberdade e a igualdade como ideais políticos ou princípios, e que tais valores se compatibilizam, respectivamente, com as $1^{\mathrm{a}}$ e $2^{\mathrm{a}}$ dimensões dos direitos humanos, quais sejam, dimensões da liberdade (direitos civis e políticos) e dimensões da igualdade (direitos econômicos, sociais e culturais).

E mais, a concepção de Rawls ainda abarcou a $3^{\mathrm{a}}$ dimensão dos direitos humanos, quando demonstrou preocupação acerca dos direitos das futuras gerações. Na seção 44 , do $5^{\circ}$ capítulo de sua obra Uma teoria da justiça, Rawls aduz que é preciso respeitar o que chamou de princípio da poupança justa, que justificaria a poupança que deveria ser feita por cada geração, em favor das que virão futuramente. Desta forma, o que hoje é distribuído precisa ser racionalmente consumido, isto é, poupado, para ser canalizado em favor das gerações futuras.

Nesse sentido, os direitos fundamentais devem ser usufruídos sem olvidar o amanhã. Quando se fala em poupança justa, diz Brito Filho (2015), não se deve associar somente a questões de ativos financeiros, pode ser pensada, naturalmente, na perspectiva do direito ao

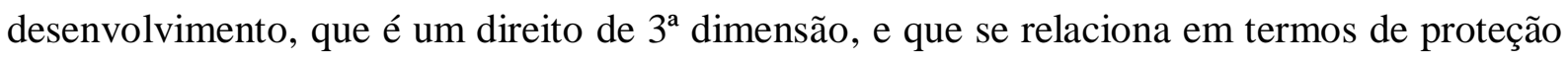
dos recursos, entre eles, os recursos ambientais, que acabam por referendar a ideia de que é necessário assegurar a solidariedade da atual geração em relação às futuras, para que estas também possam usufruir dos recursos naturais, de maneira sustentável, e assim sucessivamente.

\subsection{O DESENVOLVIMENTO SUSTENTÁVEL À LUZ DO LIBERALISMO IGUALITÁRIO DE RAWLS}

$\mathrm{Na}$ contemporaneidade, a ideia de desenvolvimento sustentável desponta como alternativa com propósito ínsito de respeito a níveis mínimos das necessidades humanas, sem descurar o imperativo do desenvolvimento, visando, em si, conjugar as dimensões ambiental, econômica, social, política e de realização de justiça social, e não apenas proclamar o mero

Rev. de Teorias da Justiça, da Decisão e da Argumentação Jurídica | e-ISSN: 2525-9644 | Porto Alegre |

v. 4 | n. 2 | p. 16 - 37 | Jul/Dez. 2018 
crescimento econômico sem preocupações com as externalidades negativas, o que, atualmente, é modelo obsoleto e vai na contramão do ideário dos países visionários.

A busca do equilíbrio entre economia, meio-ambiente e uma sociedade bemordenada e justa, para esta e para as demais gerações, é a proposta que se extrai da definição de desenvolvimento sustentável, sendo algo permeado de razoabilidade e condizente com uma ideia de justiça, tanto o é que sua definição e seus objetivos acabam por invocar, naturalmente, o propósito de desenvolver uma sociedade marcada pela justiça e pela estabilização entre conceitos como natureza, direito, política, crescimento, para as atuais e vindouras gerações.

Deste modo, dar concretude ao desenvolvimento sustentável corresponde a realizar justiça, a qual é a grande finalidade da teoria de Rawls, que visa à realização de uma sociedade justa, bem-ordenada, com instituições justas e com indivíduos capazes de buscarem a realização de seus projetos de vida por possuírem as condições necessárias para tal desiderato, ou seja, por terem ao seu alcance direitos fundamentais, situação que se busca possa ser replicada para todos os seres humanos do futuro, denotando zelo para com uma justiça entre as gerações.

O objetivo do desenvolvimento sustentável de suprir as necessidades do presente sem afetar a habilidade das gerações futuras de suprirem as próprias necessidades, é o desígnio do liberalismo de Rawls no tocante ao fato de que sua teoria busca realizar justiça no momento presente, não esquecendo as gerações futuras, que merecem viver em um ambiente propício à sua própria realização. A aspiração de justiça para o presente e para o futuro dos seres humanos é o fator de convergência entre o desenvolvimento sustentável e a teoria de Rawls, motivo pelo qual a concepção teórica rawlsiana, acredita-se, fundamenta este caminho que busca compatibilizar o ecológico, o econômico e o social, com o fim de construir uma sociedade justa.

O conceito de bens primários em Rawls, interpretados aqui como direitos fundamentais ou direitos humanos - ou seja, conjunto de direitos indispensáveis à preservação da dignidade do ser humano e para que este possa praticar os atos necessários ao cumprimento de seu plano de vida (BRITO FILHO, 2015), possuem um singular valor quando se discutem planejamento e execução de políticas públicas em sociedade. A erradicação da pobreza, da fome, o avanço nos níveis de educação, saúde, distribuição de renda, trabalho digno, dentre outros, enfim, os objetivos do desenvolvimento sustentável 
servem à consecução da justiça em sociedade, e representam preocupação mundial para com o bem-estar coletivo, para com a necessária e premente interrelação entre crescimento econômico, ambiente limpo e ecologicamente sadio.

Assim, a justiça perseguida pelo desenvolvimento sustentável e seus objetivos encontram amparo na teoria da justiça de John Rawls, na medida em que esta foi desenvolvida com o propósito de distribuir bens primários em uma sociedade bem-ordenada que tem nos valores da liberdade e igualdade as diretivas para a construção de uma justiça social no presente, e, na justiça entre gerações externalizado pelo princípio da poupança justa a preocupação para com as gerações vindouras no sentido de que também possam usufruir de uma sociedade justa.

Portanto, os objetivos primordiais do liberalismo de Rawls concernente na busca pela construção de uma sociedade bem-ordenada, guiada pelos ideais de liberdade e igualdade, com instituições justas, com indivíduos protegidos em sua dignidade e com direitos fundamentais distribuídos em níveis satisfatórios visando a que realizem seus projetos de vida, nesta e na próxima geração, são objetivos que orientam e se coadunam, estritamente, com o ideal de desenvolvimento sustentável, motivo pelo qual defende-se a teoria da justiça como equidade de Rawls como fundamento para o conceito de desenvolvimento sustentável, eis que suas linhas básicas direcionam à concepção, à realização de um valor maior, qual seja, a Justiça.

\section{CONCLUSÃO}

O presente ensaio buscou apresentar um fundamento teórico para o desenvolvimento sustentável, elegendo a teoria da justiça como equidade de John Rawls, exposta em sua obra Uma teoria de justiça, como concepção filosófica hábil ao desiderato proposto.

A partir das bases teóricas da sustentabilidade, mostrou-se que o seu conceito, apesar de indefinido, já é concebido através de uma abordagem multidisciplinar, abarcando economia, meio ambiente, bem-estar do ser humano, ética. Todos esses valores são direitos inalienáveis das gerações presentes, bem como, das gerações futuras. Além disso, a liberdade e a equidade são princípios de uma justiça social e são anseios já trabalhados por estudiosos como Rousseau, Sen e Rawls, consagrando-se como valores supremos. No Brasil, é um mandamento constitucional a ser alcançado pelo Estado, através de suas instituições e da sociedade.

Rev. de Teorias da Justiça, da Decisão e da Argumentação Jurídica | e-ISSN: 2525-9644 | Porto Alegre | v. 4 | n. 2 | p. 16 - 37 | Jul/Dez. 2018 
$\mathrm{Na}$ segunda parte da pesquisa, buscou-se concentrar na teoria da justiça como equidade proposta por John Rawls, iniciando com uma reflexão sobre o liberalismo igualitário como embasamento teórico do desenvolvimento sustentável, para, posteriormente, abordar a teoria do autor, e culminar com a apresentação da sustentabilidade à luz de tal concepção.

Desse modo, o fundamento teórico para almejar a realização do conteúdo do desenvolvimento sustentável em toda a sua complexidade e dinamicidade encontra resposta no liberalismo igualitário de Rawls. Isso porque, a teoria da justiça desse filósofo foi construída objetivando, precipuamente, a construção de uma sociedade justa, com um sistema social adequado, resultando na garantia e efetivação dos direitos fundamentais do ser humano.

A escolha de dois princípios de justiça, em uma posição original, sob o véu da ignorância, quais sejam, liberdade e igualdade - assim declinados conforme interpretação desenvolvida por Brito Filho (2015), é a base para que Rawls desenvolva toda uma construção sobre a formação de uma sociedade bem-organizada. E, quando trabalhou com o segundo princípio, abordou a questão da justiça entre gerações, dentro do princípio da poupança justa, revelando, em nosso sentir, preocupação com as gerações do amanhã, notadamente no que tange à promoção do igual acesso a bens ambientais e à sadia qualidade de vida, deixando manifesto seu zelo para com todos os presentes e às futuras gerações.

Compreender que o ideário do desenvolvimento sustentável assenta-se na adoção de medidas no presente, não apenas para que a atual geração usufrua dos recursos naturais, mais também para salvaguardar bens ambientais para as vindouras gerações, para que estas possam desfrutar de seus benefícios, é o ponto central para encontrar ressonância na teoria da justiça de Rawls, na medida em que esta caminha para fixar uma diretiva de justiça intergeracional, concernente em preservar, poupar, defender recursos ambientais no hoje para que as futuras gerações possam continuar a viver em um ambiente de equilíbrio, imprescindível para a busca de seus projetos pessoais de vida.

Frise-se que, há muito, reconheceu-se que o meio ambiente é, indiscutivelmente, concebido como um direito fundamental da pessoa, sendo parte integrante do princípio do desenvolvimento sustentável, sendo abordado como direito humano de $3^{\text {a }}$ dimensão na teoria rawlsiana, que pode ser preservado através da implementação do princípio da poupança justa, que encontra eco, justamente, no conceito de desenvolvimento sustentável.

Deste modo, a ideia de justiça em Rawls, externalizada em sua teoria da justiça como equidade, e que encontra sustentáculo na escolha de dois princípios de justiça a regerem a 
sociedade e suas instituições, e viabilizarem a que todas as pessoas busquem seus planos de vida, assim como, a definição de um princípio da poupança justa a ser implementado, especificamente, para o futuro, alcançam o propósito do desenvolvimento sustentável, razão pela qual defende-se que o liberalismo igualitário de Rawls é teoria da justiça capaz de fundamentar a concretização plena do desenvolvimento sustentável, posto que o intento central deste é a realização de justiça em sociedade, desígnio que Rawls busca em sua teoria filosófica.

Destarte, como a realização da justiça é o elo de ligação entre o desenvolvimento sustentável e o liberalismo igualitário de John Rawls, e ela é considerada um valor maior da humanidade, acredita-se que a plena efetivação do conteúdo do desenvolvimento sustentável, a partir do ideal de justiça rawlsiano, é medida que auxiliará na construção de uma sociedade socialmente justa e na manutenção de um ambiente sustentável.

\section{REFERÊNCIAS}

BENATTI, José Heder. O conceito de meio ambiente no art. $3^{\circ}$ da lei ${ }^{\circ}$ 6.938/1981. In: DIAS, Jean Carlos \& GOMES, Marcus Alan de Melo (Coord.). Direito e desenvolvimento. Rio de Janeiro: Forense; São Paulo: MÉTODO, 2014, p. 247-261.

BRITO FILHO, José Claudio Monteiro de. Direitos humanos. São Paulo: LTr, 2015.

CITTADINO, Gisele. Pluralismo, direito e justiça distributiva - Elementos da filosofia constitucional contemporânea. $4^{\mathrm{a}}$ ed. $2^{\mathrm{a}}$ tiragem. Rio de Janeiro: Lumen Juris, 2013.

DAHL, Arthur Lyon. Putting the individual at the center of development: indicators of wellbeing for a new social contract. In: Transitions to sustainability. Editors: MANCEBO, François; SACHS, Ignacy. New York; London: Springer, 2015.

DWORKIN, Ronald. A raposa e o porco-espinho: justiça e valor. Tradução: Marcelo Brandão Cipolla. São Paulo: Editora WMF Martins Fontes, 2014.

FLEISCHACKER, Samuel. Uma breve história da justiça distributiva. Tradução: Álvaro de Vita. São Paulo: Martins Fontes. Coleção justiça e direito, 2006.

FREITAS, Juarez. Sustentabilidade: direito ao futuro. 2.ed. Belo Horizonte: Editora Fórum, 2012.

Sustentabilidade: direito ao futuro. 3.ed. Belo Horizonte: Editora Fórum, 2016.

Rev. de Teorias da Justiça, da Decisão e da Argumentação Jurídica | e-ISSN: 2525-9644 | Porto Alegre | v. 4 | n. 2 | p. 16 - 37 | Jul/Dez. 2018 
LOPES, Carlos. Rousseau, Rio and the green economy. In: Transitions to sustainability. Editors: MANCEBO, François; SACHS, Ignacy. New York; London: Springer, 2015.

MANCEBO, François. Insights for a better future in an unfair world: combining social justice with sustainability. In: Transitions to sustainability. Editors: MANCEBO, François; SACHS, Ignacy. New York; London: Springer, 2015.

MONTIBELLER FILHO, Gilberto. Ecodesenvolvimento e desenvolvimento sustentável: conceitos e princípios. Revista Textos de Economia. v. 4. n. 1. UFSC. Florianópolis, 1993.

OLIVEIRA, Nythamar de. Rawls. Rio de Janeiro: Jorge Zahar Ed., 2003.

ORGANIZAÇÃOS DAS NAÇÕES UNIDAS (ONU). Nações Unidas no Brasil. Objetivos do desenvolvimento sustentável. Disponível em: http://www.br.undp.org/content/brazil/pt/home/library/ods/cartilha-de-perguntas-e-respostasdos-ods.html. Acesso em: 01 set. 2018.

RAWLS, John. Uma teoria da justiça. Tradução: Almiro Pisetta e Lenita Maria Rímoli Esteves. $2^{a}$ ed. - São Paulo: Martins Fontes. Coleção justiça e direito, 2002.

SCALOPPE, Luiz Alberto Esteves. A participação política no pensamento liberal: Rawls e Dworkin. Revista jurídica da Presidência da República. Brasília, vol. 16, no 110, Out. 2014/Jan. 2015, p. 799-822. Disponível em: https://revistajuridica.presidencia.gov.br/index.php/saj/article/view/57/48. Acesso em: 01 set. 2018.

SEN, Amartya. Desenvolvimento como liberdade. São Paulo: Companhia das Letras, 2000.

TEIXEIRA, José Elaeres Marques. Liberdades iguais Rawls. Revista jurídica da Presidência da República. Brasília, vol. 9, $\mathrm{n}^{\circ}$ 85, jun./jul. 2007, p. 40-62. Disponível em: https://revistajuridica.presidencia.gov.br/index.php/saj/article/view/303/296. Acesso em: 01 set. 2018.

VEIGA, José Eli da. Sustentabilidade: a legitimação de um novo valor. São Paulo: Editora Senac, 2010.

VITA, Álvaro de. Justiça liberal: argumentos liberais contra o neoliberalismo. Rio de Janeiro: Paz e Terra, 1993.

A justiça igualitária e seus críticos. $2^{\mathrm{a}}$ ed. - São Paulo: WMF Martins Fontes. Coleção justiça e direito. 2007. 